\title{
Customer service expectations in retail banking in Africa
}

\author{
G. Bick \\ Coca Cola Chair of Marketing, Graduate School of Business Administration, \\ University of the Witwatersrand, PO Box 98, Wits 2050, Republic of South Africa \\ R. Abratt* \\ Huizenga School of Business and Entrepreneurship, Nova Southeastern University and \\ Wits Business School, University of the Witwatersrand, 3301 College Avenue, \\ Ft. Lauderdale, Florida 33314, USA \\ abratt@huizenga.nova.edu \\ D. Möller \\ Graduate Researcher \\ Wits Business School, University of the Witwatersrand, P O Box 98, Wits 2050, Republic of South Africa
}

\section{Received November 2009}

\begin{abstract}
There has been very little research on customer service in the African continent. This paper determines and analyses customer service expectations of 4035 clients in retail banking across 10 African countries. In addition country differences in customer service expectations are identified. A quantitative research design was followed. Bank customers in banking halls were intercepted and interviewed about their service expectations at their bank. The survey instrument used was a questionnaire developed from the SERVQUAL model. A comparative scaling technique applying a partial rank order scale was used. The results show customer service expectations differ significantly between countries in Africa. Overall in Africa the dimension 'responsiveness' was the most important service requirement for retailing bank customers, followed by 'reliability of service'. However, when analysing results by country clear differences and similarities emerge. It is important for Banks to take cross-national differences into consideration when designing and implementing a global marketing strategy, or even a Pan-African marketing strategy. Relational issues surrounding assurance and empathy are of less importance in an African context.
\end{abstract}

*To whom all correspondence should be addressed.

\section{Introduction}

Services have been the fastest growing segment of the world economy, particularly in developing countries, creating many opportunities for different service-related firms (Malhotra, Ulgado, Agarwal, Shainesh \& Wu, 2005). A critical service for the development of an economy is the provision of banking services. Many developing countries have well-established banking infrastructure and branch networks (Greenland, Coshall \& Combe, 2006). For banks to thrive, both product and service delivery must be adequately aligned with customer expectations: achieving customer satisfaction and loyalty is essential for long-term survival (Reichheld, 2003). In retail banking, service quality is a crucial aspect of the customer experience. However, while banking service quality has been extensively researched in developed economies, there is a comparative dearth of studies pertaining to developing economies (Sureshchandar, Rajendran \& Anantharaman, 2003), and in particular in Africa. In addition, culture is also likely to be a key variable affecting perceptions and expectations of service quality (Malhotra et al., 2005). This paper helps to provide insights into banking service quality in developing economies.

The purpose of this study is to determine and analyse the cross-national differences in customer service expectations within the retail banking sector, across ten African countries. Understanding customer expectations in the African continent is a major opportunity for Banks in Africa driven by some of the high growth economies in developing countries and a general lack of information readily available.

\section{Literature review}

Cross-national differences in service expectations and perceptions

Johnson and Mathews (1997) emphasise the importance of understanding customer expectations as a first step in improving service quality. Johnson and Mathews (1997) also point out that expectations can vary according to culture, for example in their study they found that "security" was perceived as the highest expectation base in the UK, 
whilst "reliability" was the most important quality dimension to US consumers.

A number of authors have identified cross-national differences in service expectations. While Webster (1989) discovered the importance of demographics on expectations in the USA, Johnson and Mathews (1997) argue that there are other factors that could influence expectations which have yet to be investigated empirically. Davidow and Uttal note: (1998:25) "Service expectations are formed by many uncontrollable factors, from the experience of customers ... to a customer's psychological state at the time of service delivery."

The importance of taking cross-national differences in service expectations into consideration when designing and implementing a marketing strategy is critical for multinational companies expanding into new markets or facing increasing competition in existing international operations. Lovelock (1999) shows that in developing a transnational service strategy, management must decide which, if any, supplementary elements should be consistent across all markets and which might be tailored to meet local needs, expectations and competitive dynamics. Speece and Pinkaeo (2002) described the differences in customer expectations based on ethnocentrism in Thailand compared to other countries. Espinoza (1999) indicates that service managers need to be cognizant of the parts of the service delivery experience that are open to cultural influences as contrasted with those that remain stable across cultures. For example, he found "responsiveness" was the most important dimension for Quebecers while "tangibles" was the most important for Peruvians. Differences in service expectations are relevant and need to be considered when designing a marketing strategy.

Knight (1999:356), identified the growing importance of international services and highlighted the need for additional research into the international marketing of services. In particular, he highlights "a key challenge is overcoming hurdles associated with the unique characteristics of each country and the fact that services are particularly prone to culture and other country-specific influences. Services are fundamentally people-centered and are therefore highly culture-sensitive."

Consumers of services in different countries may have different perceptions of service quality due to cultural differences (Malhotra et al., 2005). In a study of banking services in the USA, India and the Philippines, Malhotra et al. (2005) found that there were systematic and significant differences in perception of service quality dimensions between developed and developing countries, that could be predicted based on economic, cultural and social factors. Similarly, in a comparison of Greek and Bulgarian bank service quality (developed versus developing countries), Petridou, Spathis, Glaveli and Liassides (2007) found that Greek customers perceived a higher quality of service than the perceptions of their Bulgarian counterparts, due to different political, economic and socio-cultural environments.
However, other studies of banking service quality have found congruence between different cultural groups, suggesting that service quality measures developed in one culture may capture service quality sentiments in another culture (Karatepe, Yavas \& Babakus, 2005; Yavas \& Benkenstein, 2007).

Stauss and Mang (1999) identified the possibility that the perceived service encounter differs among customers from different cultures. Stauss and Mang (1999) point out that there is hardly any prior discussion about the fact that customers with different cultural backgrounds may have different expectations toward service encounters and that they may perceive these situations differently. Smith and Reynolds (2002:405) state that "Cultural differences may also explain variations in consumers' reported perceptions of a service".

In considering the growing importance of understanding cross-cultural differences, it is useful to consider Tersine and Harvey (1998:45), who point out that "Trade liberalization, expanding global markets, and technology proliferation" require organisations to "confront the need for a fundamental change in the way products and services are designed, produced, and delivered to customers". This importance is growing with the ongoing growth of global business and global service business in particular. International trade in services has shown a growth rate of $18 \%$ percent and today makes one-fifth of all world trade (World Trade Organisation, 2005). Increasing globalisation results in more service companies who conduct their business with customers of different cultures. For these multinational companies it is becoming increasingly important to determine whether there are differences among the service expectations and what form these differences take. We therefore table the following proposition:

Proposition 1: Customer service expectations differ significantly between countries in Africa.

Service quality, service expectations and
perceptions

In response to the growing importance of services in the worldwide economy, and the recognition by firms for the need to compete on the service dimensions of the augmented product, several researchers have examined the problems of measuring and managing service quality (Baumann, Burton, Elliott \& Kehr, 2007; Bitner, Booms \& Tetreault, 1990; Boulding, Kalra, Staelin \& Zeithaml, 1993; Gilbert \& Veloutsou, 2006; Parasuraman, Berry \& Zeithaml, 1985, 1988, 1990, 1991, 1993; Robledo, 2001).

Customer expectations constitute an integral part of service quality evaluations. In order to manage service quality, a strategic effort should be made at company level to understand and manage their customer's expectations and perceptions regarding the quality of service delivered in daily interactions. Pitt, Morris and Oosthuizen (1996) demonstrated that different members of buying centres have different expectations of the quality of service for a high tech product and suggest that industrial marketers may wish 
to focus on these as an additional way to gaining insight for marketing strategy.

Robledo (2001) suggests that perceived quality constitutes two components: namely, customer perceptions and expectations. Perceptions of the dimensions of service quality are viewed to be a function of a customer's prior expectations of what will and what should transpire during a service encounter, as well as the customer's most recent contact with the service delivery system (Boulding et al., 1993). Parasuraman et al. (1991) and Robledo (2001) suggest that understanding customer expectations is a prerequisite for delivering superior service, since customers evaluate a firm's service quality by comparing their perceptions of the service with their expectations.

\section{Service quality expectations in the retail banking sector}

The Zeithaml, Parasuraman and Berry (1990) study asked users of credit cards and retail banking services, amongst users of other products/ services, to rate the importance of each service dimension. The results indicated that reliability of service was the most important requirement of these financial service customers. The second most important requirement for credit card customers was responsiveness and bank customers' empathy.

However Bitner et al. (1990) identified employees' willingness to respond to a problem and their employees' responsiveness to customer needs as key factors in service quality. Avkiran (1994) in a study of an Australian trading bank, found elements of credibility and responsiveness to be the most important.

According to a study in the UK by Blanchard and Galloway (1994), the breakdown of the SERVQUAL dimensions also show responsiveness as the most important service dimension, followed by assurance, empathy, tangibles and reliability. Johnston (1997) later confirmed this, identifying responsiveness to be the most important service dimension in the UK retail banking sector. In a study of retail banks in North Cyprus, Karatepe et al. (2005), developed their own scale comprising 4 dimensions, and found the relative importance was 1. interaction quality (similar to the responsiveness and assurance dimensions), 2. empathy, 3. reliability, and 4. service environment (similar to tangibles). We thus posit the following proposition:

Proposition 2: The importance ranking of service dimensions in African retail banking are: 1. Responsiveness; 2. Assurance; 3. Empathy; 4 ${ }^{=}$Tangibles and Reliability.

\section{Use of SERVQUAL}

The SERVQUAL model has been criticised for a number of reasons: the use of so-called "difference scores" (Quality = Perceptions - Expectations), the ambiguity of the definition of "consumer expectations", the stability of the scale over time, and the dimensionality of the instrument (Ladhari, 2008). It has been extended to include a "Zone-ofTolerance" measure, to address some of the limitations.
There have also been arguments for industry-specific measures of service quality, and for measures to take in cultural differences (Imrie, Cadogan \& McNaughton, 2002). Arasli, Katircioglu and Mehtap-Smadi (2005) compared service quality across Greek- and Turkish-speaking areas in Cyprus. The study found that the responsiveness dimension failed to load, and thus the SERVQUAL scale proved to be a four-dimensional structure in this study. Yavas and Benkenstein (2007) compared Turkish and German bank customers, and found that the SERVQUAL items decomposed into three factors for both groups. They also found strong congruence between the two groups, suggesting that a standardised SERVQUAL model could be used in different cultures without developing specific measures from scratch. Bhat (2005) used SERVQUAL in a study of 5 Northern Indian banks, and found that Indian banks delivered poorer service quality than foreign banks, mostly because of deficiency in tangibility and responsiveness. Islam and Ahmed (2005) used SERVQUAL in assessing the quality of banks in Dhaka City of Bangladesh, and found that the most important service quality factor of banks is personal attention to the clients, followed by error-free records, safety in transaction, and tangible physical facilities of the bank.

Jabnoun and Khalifa (2005) used the 5 dimensions of SERVQUAL plus two other dimensions called values (the extent to which the services of an organization fit the values of customers) and image to measure service quality in UAE conventional and Islamic banks in Dubai and Sharjah. Factor analysis resulted in four dimensions: Personal skills (from the original dimensions of Responsiveness, Assurance and Empathy), Reliability, Values and Image. Jabnoun and Al-Tamimi (2003) conducted a similar study using SERVQUAL, and found 3 dimensions: Human skills (including assurance, reliability and responsiveness), Tangibles and Empathy. Najjar and Bishu (2006) used SERVQUAL in studying service quality in two banks in Nebraska, and found that reliability and responsiveness are the two most critical dimensions of service quality. Consequently, while SERVQUAL has been criticised and developed to include industry-specific and cultural differences, it has been extensively proven in the banking industry in recent studies. Comparing some 30 studies of service quality across various industries, Ladhari (2008) found considerable empirical support for the use of SERVQUAL. As a result, the SERVQUAL model was utilised in this study to measure service quality across retail banks in 10 African countries.

\section{Methodology}

This study follows a quantitative research methodology. Bank customers in ten African countries were asked about their service expectations in a retail bank. The measuring instrument was a survey questionnaire adapted from the SERVQUAL model (Parasuraman, Zeithaml \& Berry, 1994) in order to ensure a valid construct. The intent was not to evaluate SERVQUAL but rather to investigate customer service expectations across African countries, as little is known about it. The dimensional stability of the SERVQUAL model is generally stable (Carman, 1990). This instrument has been used in a number of recent 
banking studies and was found to be valid and reliable (Baumann et al., 2007; Lassar et al,. 2000). It also has been applied to South African conditions, and also found to be generally both valid and reliable (Boshoff \& Nel, 1992; Nel, Pitt \& Berthon, 1997). A comparative scaling technique applying a partial rank order scale was used in the questionnaire to determine the top three most important service attributes (in order of importance), out of fifteen attributes.

The SERVQUAL model was used as a framework for the questionnaire design and analysing the data. The questionnaire was adapted from the SERVQUAL dimensions i.e. reliability, tangibles, responsiveness, assurance, and empathy. Table 1 shows the mapping of the fifteen service attributes to the SERVQUAL dimensions.

\section{The questionnaire}

The surveys comprised a structured questionnaire, administered face-to-face using intercept interviews as the primary methodology. The first part of the questionnaire addressed demographic data which was used for narrative purposes only. The second part of the questionnaire used a partial rank order scale, which lists fifteen key service attributes in accordance with the SERVQUAL requirements (Parasuraman et al., 1994). Respondents were asked to rank the top three attributes in order of importance.

\section{Population and sample}

The targeted population for this study was limited to retail banking customers, from the capital cities of ten countries and is shown in table 2. The ten countries were selected due to the presence of a Barclays bank branch in that country.

Access to the primary population was achieved by selected in-country market research consultancy companies specialising in the financial sector. In-country research vendors were coordinated from South Africa by a leading market research group. The sample size by country is shown in table 3, including a breakdown of bank branch customers (an average of $73 \%$ of respondents) and non-customers (average $27 \%$ of respondents).

A random sample of retail banking customers was selected in each country by bank branch intercepts. The use of some basic selection rules guided the intercepts. The interviews were done mainly during the week. The day was then divided into time slots and a time slot was randomly selected to start interviewing in. A person was intercepted every nth minute (where $\mathrm{n}$ was randomly determined) for an interview to ensure randomness. If a respondent was unwilling / unavailable to assist in the case of the intercept interviewing, the interviewer was instructed to interview the next respondent exiting the branch.

\section{Data collection}

Since customer databases were not available for the envisaged samples, it was necessary to use face-to-face interviews as a means of contact. This technique allowed for a higher response rate and is more convenient for the respondent. However, apart from the economical and logistical disadvantages of this technique, it should be kept in mind that some respondents would still give biased responses when face-to-face with a researcher. Furthermore, language translation may reduce face validity.

Face-to-face intercept interviewing was conducted in every country. Respondents were recruited in banking halls or as they left the premises of the banks by first intercepting them and then conducting the face-to-face interview. The following quality controls were put in place: face-to-face briefings were done in every country; pilot interviews were conducted in each country; $20 \%$ telephonic back checks were conducted in every country; research was conducted in accordance with the code of ethics prescribed by the European Society for Opinion and Marketing Research (ESOMAR), and the South African Marketing Research Association (SAMRA); and coding was centralised in South Africa to produce a standardised code frame. The interview / information quality was greatly enhanced as the interviews could be conducted in English or the local language, depending on the respondent's preference. The questionnaires were translated into the languages depicted in Table 4.

\section{Data analysis}

Respondents were required to rank order (in order of importance) the top three most important service attributes relating to their bank, out of 15 service attributes in total. The data was summarised by tabulating the frequency (and proportion) of occurrence of each preference permutation. Once the mean and standard deviations were derived, the methodology made use of hypothesis ANOVA testing, ttests and importance ranking to determine whether crossnational differences in service expectations exist, and what service attributes proposed by retail banks are considered most important to customers. 
Table 1: Mapping of service attributes to SERVQUAL dimensions

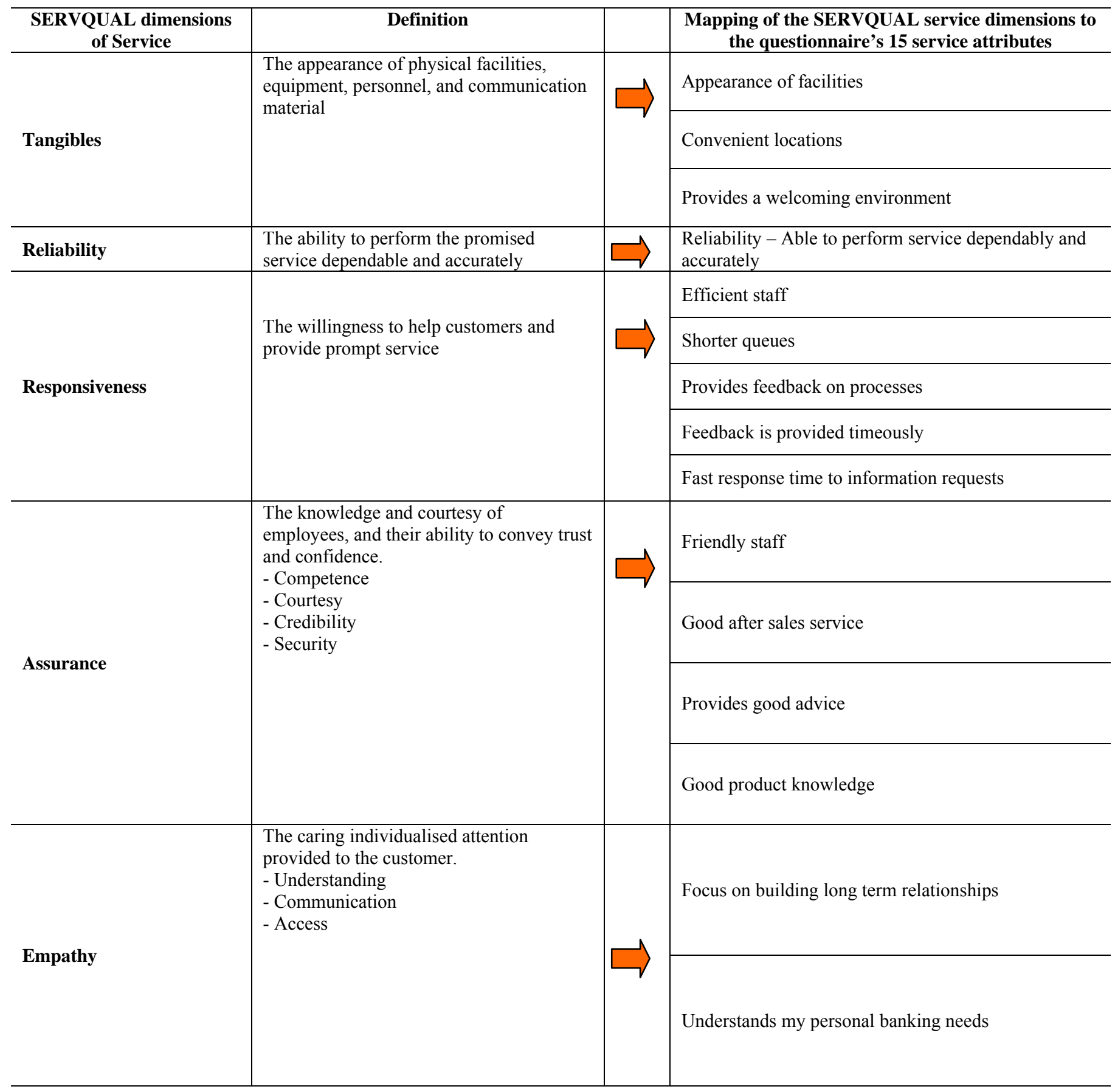


Table 2: Surveyed countries and respective retail banks

\begin{tabular}{|c|c|c|c|c|c|c|}
\hline Country & Bank 1 & Bank 2 & Bank 3 & Bank 4 & Bank 5 & Bank 6 \\
\hline Botswana & Barclays Bank & $\begin{array}{l}\text { First National } \\
\text { Bank }\end{array}$ & $\begin{array}{l}\text { Standard } \\
\text { Chartered }\end{array}$ & Stanbic & BBS & \\
\hline Egypt & Barclays Bank & MISR & NSGB & Citigroup & HSBC & CIB \\
\hline Ghana & Barclays Bank & Ecobank & $\begin{array}{l}\text { Standard } \\
\text { Chartered }\end{array}$ & $\begin{array}{l}\text { Ghana Commercial } \\
\text { Bank }\end{array}$ & SSB & \\
\hline Kenya & Barclays Bank & $\begin{array}{l}\text { Standard } \\
\text { Chartered } \\
\end{array}$ & $\mathrm{KCB}$ & Co-Operative Bank & $\begin{array}{l}\text { National Bank } \\
\text { of Kenya }\end{array}$ & \\
\hline Mauritius & Barclays Bank & $\begin{array}{l}\text { Mauritius } \\
\text { Commercial } \\
\text { Bank }\end{array}$ & $\begin{array}{l}\text { State Bank } \\
\text { Mauritius }\end{array}$ & HSBC & First City Bank & \\
\hline Seychelles & Barclays Bank & $\begin{array}{l}\text { Seychelles } \\
\text { Savings Bank }\end{array}$ & Nouvobanq & MCB & & \\
\hline Tanzania & Barclays Bank & $\begin{array}{l}\text { National Micro- } \\
\text { financial Bank }\end{array}$ & $\begin{array}{l}\text { Standard } \\
\text { Chartered }\end{array}$ & $\begin{array}{l}\text { Co-operative Rural } \\
\text { Development Bank }\end{array}$ & $\begin{array}{l}\text { National Bank } \\
\text { of Commerce }\end{array}$ & \\
\hline Uganda & Barclays Bank & DFCU Bank & $\begin{array}{l}\text { Standard } \\
\text { Chartered }\end{array}$ & Stanbic & Nile Bank & \\
\hline Zambia & Barclays Bank & $\begin{array}{l}\text { Standard } \\
\text { Chartered }\end{array}$ & Stanbic & Zanaco & Citibank & \\
\hline Zimbabwe & Barclays Bank & $\begin{array}{l}\text { Standard } \\
\text { Chartered }\end{array}$ & Stanbic & $\begin{array}{l}\text { Zimbabwe } \\
\text { Amalgamated } \\
\text { Banking Group }\end{array}$ & Zimbank & Jewel Bank \\
\hline
\end{tabular}

Table 3: Sample size by country

\begin{tabular}{c|c|c|c|c}
\hline Country & Percentage by country & Total No. Interviews & $\begin{array}{c}\text { Bank branch customers } \\
\mathbf{( \% )}\end{array}$ & Non-customers (\%) \\
\hline Botswana & 13 & 540 & $73 \%$ & $27 \%$ \\
\hline Egypt & 8 & 315 & $71 \%$ & $29 \%$ \\
\hline Ghana & 12 & 490 & $72 \%$ & $28 \%$ \\
\hline Kenya & 15 & 550 & $72 \%$ & $28 \%$ \\
\hline Mauritius & 9 & 380 & $79 \%$ & $21 \%$ \\
\hline Seychelles & 5 & 200 & $80 \%$ & $20 \%$ \\
\hline Tanzania & 6 & 250 & $76 \%$ & $24 \%$ \\
\hline Uganda & 8 & 330 & $71 \%$ & $29 \%$ \\
\hline Zambia & 12 & 490 & $71 \%$ & $29 \%$ \\
\hline Zimbabwe & 12 & 490 & $\mathbf{7 3 \%}$ & \\
\hline Total & $\mathbf{1 0 0}$ & $\mathbf{4 0 3 5}$ & $\mathbf{2 7 \%}$ \\
\hline
\end{tabular}

Table 4: Questionnaire translation by country

\begin{tabular}{l|c}
\hline Country & Translation \\
\hline Botswana & English / Setswana \\
\hline Egypt & Arabic \\
\hline Ghana & English / Twi \\
\hline Kenya & English / Kiswahili \\
\hline Mauritius & English / French and Mauritian Creole \\
\hline Seychelles & English / Seychelles Creole \\
\hline Tanzania & English / Kiswahili \\
\hline Uganda & English / No translation \\
\hline Zambia & English / No translation \\
\hline Zimbabwe & English / No translation \\
\hline
\end{tabular}

\section{Validity and reliability}

Content validity was addressed by ensuring that there were adequate questions to completely cover all the relevant aspects identified in the literature review. Questionnaire wording / understanding across different cultural boundaries may weaken face validity. This was addressed by translating and conducting face-to-face interviews in English or the home language, depending on the respondent's choice, in an effort to reduce misinterpretations. Construct validity was addressed by means of questionnaire piloting. This ensured that constructs were clear, unambiguous and did not result in bias as a result of phrasing. Each construct was developed to add value to the survey, and was selected to ensure convergence with the literature review. The task of rank ordering large numbers of items can be unduly onerous for respondents, which has a negative impact on the validity and reliability of the data. This issue was addressed by using 
partial rank ordering in the questionnaire in order to reduce respondent fatigue.

Reliability of the research was achieved using a standard questionnaire to ensure consistency, so that all respondents were asked identical questions. By constructing the survey questionnaire derived from the SERVQUAL model, as well as the literature review, it was possible to enhance internal consistency through the use of rank order scales (Leedy \& Ormrod 2001) rather than qualitative content analysis resulting from open-ended questions. Errors of equivalence and stability were also reduced since responses were selected from a limited range of clearly defined service attributes. The quality controls also ensured that the research was administered consistently throughout all the countries. A quantitative research methodology using a random sampling technique and adequate sample sizes reduced the potential for sampling error and ensured that the outcomes have a greater degree of reliability.

\section{Results}

\section{Cross national differences}

For multinational companies, it is becoming increasingly important to determine whether there are differences across countries in service expectations, and what form these differences take. Users of retail banking services were read a list of 15 service attributes relating to their bank, and asked to rank the top three most important service attributes. The findings in Table 5 show that in all cases (15 attributes), the zero hypothesis is rejected based on the low $\mathrm{p}$ values.

Thus, there is sufficient evidence to indicate that for every service attribute, one or more of the population (country) means are not equal to the others. Every attribute had some significant difference between countries. This implies that different cultural groups give different importance to service quality dimensions.

This finding supports the proposition that customer service expectations in retail banking differ significantly between countries in Africa. It is therefore critical to take crossnational differences into consideration when designing and implementing a marketing strategy for multinational companies. In order to achieve this, country-specific customer expectations must be investigated and prioritised as a first step towards improving service quality.

\section{Importance Ranking of Service dimensions and Attributes}

In order to better understand what form these cross-national differences take, the following tests were carried out in order to highlight the similarities and differences in customer service expectations.

Respondents ranked in descending order (i.e. first most important, second most important and third most important) the top three most important service attributes relating to their bank, out of 15 service attributes in total. The data was then ranked by service attribute and the underlying service dimension. In the ranking, the higher the mean, the more important that aspect of service delivery is to the respondents. Negative means have a less than average importance. An overall mean was derived from the individual country means. No weighting was applied to the overall mean in order to give each country equal importance.

The individual attributes have been clustered into the underlying SERVQUAL dimensions, and the overall mean for all countries is presented in Table 6 .

\section{Overall results for Africa}

Results from the analysis of the SERVQUAL dimensions clearly indicate that "responsiveness" is the most important service requirement for retail banking customers, followed by "reliability of service", "tangibles", "assurance" and "empathy". Analysis of the individual attributes indicates that staff efficiency is by far the most important service criterion for retail banking customers in Africa. Shorter queues, service reliability and convenient locations are the second, third and fourth most important attributes respectively. The underlying service dimension "responsiveness" is essentially the time dimension of service quality, and reflects issues relating to the bank's willingness to help customers and provide prompt service. Three out of five "responsiveness" attributes are ranked in the top 5. It is interesting to note that respondents assign considerably more importance to staff efficiency than any other attribute. On average, respondents perceive staff efficiency to be twice as important in comparison to the second highest ranked attribute (shorter queues). "Responsiveness" as a dimension is perceived to be of serious importance, ranked first out of the five service dimensions. While responsiveness is typically process based, one could argue that in this case both attributes driving this dimension relate to the time aspect of service delivery (rather than willingness to help). Thus, this dimension is more outcomes based, and could be classified as an objective hard issue that banks must deal with.

The underlying service dimension "reliability" reflects issues relating to the bank's ability to perform the promised service dependably and accurately. The results show that in an African environment, this dimension is ranked second most important by users of retail banking services. Reliability is outcome based (Grönroos, 1988) and can be classified as an objective hard issue since it can be much more readily identified and specified to that of soft and subjective "relational" issues.

The underlying service dimension "tangibles" reflects issues relating to the appearance of physical facilities, location and personnel. Respondents identified convenient locations to be very important, however they were less concerned with appearance of facilities and a welcoming environment, which received a below average rating. 
Table 5: Service Attributes by Country

\begin{tabular}{|c|c|c|c|c|c|c|c|c|c|c|c|}
\hline \multirow[t]{2}{*}{ Service Attributes } & \multicolumn{10}{|c|}{ Sample Means } & \multirow[t]{2}{*}{ P Value } \\
\hline & Bots & Egypt & Ghana & Kenya & Maur & Seych & $\operatorname{Tanz}$ & Ugan & Zam & Zim & \\
\hline 1. Efficient staff & 1,101 & 0,988 & 0,800 & 0,779 & 0,518 & 0,882 & 0,864 & 0,836 & 0,905 & 0,769 & 0,000 \\
\hline 2. Shorter queues & 0,416 & 0,925 & 0,403 & 0,249 & 0,409 & 0,259 & 0,544 & 0,278 & 0,245 & 0,399 & 0,000 \\
\hline 3. Convenient locations & 0,015 & 0,161 & 0,354 & 0,481 & $-0,065$ & $-0,068$ & 0,285 & 0,475 & 0,419 & 0,318 & 0,000 \\
\hline 4. Friendly staff & 0,022 & 0,117 & 0,586 & 0,069 & 0,299 & 0,019 & 0,480 & 0,203 & 0,191 & $-0,141$ & 0,000 \\
\hline 5. After sales service & $-0,313$ & 0,048 & $-0,360$ & $-0,282$ & 0,043 & 0,513 & $-0,453$ & $-0,343$ & $-0,201$ & $-0,165$ & 0,000 \\
\hline $\begin{array}{l}\text { 6. Response time to info } \\
\text { requests }\end{array}$ & $-0,066$ & 0,428 & 0,165 & 0,322 & 0,303 & 0,510 & $-0,119$ & 0,094 & 0,037 & 0,167 & 0,000 \\
\hline 7. Reliability & 0,419 & 0,066 & 0,234 & 0,761 & 0,114 & $-0,022$ & 0,097 & 0,342 & 0,422 & 0,610 & 0,000 \\
\hline $\begin{array}{l}\text { 8. Appearance of } \\
\text { facilities }\end{array}$ & $-0,357$ & $-0,477$ & $-0,303$ & $-0,250$ & $-0,173$ & $-0,370$ & $-0,168$ & $-0,375$ & $-0,326$ & $-0,571$ & 0,000 \\
\hline $\begin{array}{l}\text { 9. Building long term } \\
\text { relationships }\end{array}$ & $-0,356$ & $-0,222$ & $-0,249$ & 0,088 & $-0,257$ & $-0,254$ & $-0,224$ & $-0,190$ & 0,030 & 0,018 & 0,000 \\
\hline $\begin{array}{l}\text { 10. Understands personal } \\
\text { banking needs }\end{array}$ & 0,236 & 0,352 & $-0,080$ & 0,383 & 0,173 & 0,176 & $-0,299$ & 0,304 & 0,127 & 0,438 & 0,000 \\
\hline 11. Provides good advice & $-0,232$ & $-0,348$ & $-0,255$ & $-0,166$ & 0,063 & 0,269 & $-0,399$ & $-0,324$ & $-0,172$ & $-0,318$ & 0,000 \\
\hline $\begin{array}{l}\text { 12. Provides a } \\
\text { welcoming } \\
\text { environment }\end{array}$ & $-0,487$ & $-0,810$ & $-0,447$ & $-0,542$ & $-0,177$ & $-0,266$ & $-0,299$ & $-0,672$ & $-0,288$ & $-0,799$ & 0,000 \\
\hline $\begin{array}{l}\text { 13. Provides feedback on } \\
\text { processes }\end{array}$ & $-0,178$ & $-0,204$ & $-0,241$ & $-0,190$ & $-0,169$ & $-0,044$ & $-0,004$ & $-0,334$ & $-0,585$ & 0,089 & 0,000 \\
\hline $\begin{array}{l}\text { 14. Feedback is provided } \\
\text { timeously }\end{array}$ & $-0,181$ & $-0,716$ & $-0,167$ & $-1,023$ & $-0,534$ & $-0,838$ & 0,059 & 0,109 & $-0,446$ & $-0,269$ & 0,000 \\
\hline $\begin{array}{l}\text { 15. Good product } \\
\text { knowledge }\end{array}$ & $-0,040$ & $-0,309$ & $-0,440$ & $-0,677$ & $-0,547$ & $-0,766$ & $-0,364$ & $-0,404$ & $-0,359$ & $-0,546$ & 0,000 \\
\hline
\end{tabular}

Note assumptions:

- The data has been standardised, therefore the overall mean $=0$, and the overall standard deviation $=1$

- Each of the samples is drawn from a normal population

- Central Limit theorem can be used as the basis for normality due to large sample sizes

- The samples are independent and selected at random

- Variance (or standard deviation) of the items (populations) are equal

- Significance level: $5 \%(\alpha=0.05)$

The underlying service dimension "assurance" reflects issues relating to the knowledge and courtesy of employees, and their ability to convey trust and confidence i.e. friendly staff, good advice, product knowledge and after sales service. Of all the "assurance" attributes, respondents only perceived friendly staff to be of some importance (slightly above average), whilst good advice, product knowledge and after sales service was of little importance. The results show that "assurance" is only ranked fourth in an African context.

The underlying service dimension "empathy" reflects issues relating to the caring, individualised attention provided to the customer; i.e. understanding the customer's personal banking needs, and building long term relationships. Understanding personal banking needs was the only "empathy" attribute to be of some importance. The literature review showed that "empathy" is typically ranked third in a retail banking environment. The results indicate that in an African context, this dimension is the least important, ranked fifth by users of retail banking services.

\section{Country-specific results}

When analysing the results by country, shown in Table 7, clear similarities and differences emerge.

Efficient staff was rated as the most important service attribute for all ten countries. Thereafter, the second and third most important service attributes varied significantly by country. By implication, "responsiveness" is therefore the most important dimension for every country. However subsequent rankings of service dimensions also vary by country. In summary, responsiveness was the most important dimension for Africa overall, driven by staff efficiency and shorter queues. The results also suggest that relational issues surrounding assurance and empathy are of less importance in an African context. The key attributes identified (staff efficiency, shorter queues, and reliability) tend to be more outcome based and can be classified as objective hard issues since they can be much more readily identified and specified than that of soft and subjective "relational" issues. This implies that addressing the hard objective issues could more readily provide, and monitor, a high quality service in a fairly prescriptive and reproducible manner (Blanchard \& Galloway, 1994).

Furthermore, cross-country analysis shows partial indifferences in the relative importance regarding dimensions and attributes. Staff efficiency/ responsiveness was the most important attribute/ dimension for each and every country, indicating that partial similarities of relative importance across countries do exist. This would suggest that efforts to increase speed of processing information and customers are likely to have an important and positive effect on customer satisfaction. 
Table 6: Importance ranking of overall means, by service dimensions and attributes

\begin{tabular}{|c|c|c|c|c|}
\hline Dimensions & Service Attributes & Overall Mean & Rank: Attribute & Rank: Dimension \\
\hline \multirow[t]{5}{*}{ Responsiveness } & Efficient staff & 0,844 & 1 & \multirow{5}{*}{1} \\
\hline & Shorter queues & 0,413 & 2 & \\
\hline & Provides feedback on processes & $-0,186$ & & \\
\hline & Feedback is provided timeously & $-0,401$ & & \\
\hline & Response time to info requests & 0,184 & $5=$ & \\
\hline Reliability & Reliability & 0,304 & 3 & 2 \\
\hline \multirow[t]{3}{*}{ Tangibles } & Appearance of facilities & $-0,337$ & & \multirow{3}{*}{3} \\
\hline & Convenient locations & 0,237 & 4 & \\
\hline & Provides a welcoming environment & $-0,479$ & & \\
\hline \multirow[t]{4}{*}{ Assurance } & Friendly staff & 0,184 & $5=$ & \multirow{4}{*}{4} \\
\hline & After sales service & $-0,151$ & & \\
\hline & Provides good advice & $-0,188$ & & \\
\hline & Good product knowledge & $-0,445$ & & \\
\hline \multirow[t]{2}{*}{ Empathy } & Building long term relationships & $-0,161$ & & \multirow{2}{*}{5} \\
\hline & Understands personal banking needs & 0,181 & 7 & \\
\hline
\end{tabular}

Note:

- For the overall mean, no weighting was applied in order to give each country equal importance

- The data has been standardised, therefore the overall mean $=0$, and the overall standard deviation $=1$

- The higher the mean, the more important that aspect of service delivery is to the respondents Negative means are inconsequential since they represent a less than average importance

\section{Significance of attribute means}

Hypothesis t-tests were used to determine the significance of each attribute, for the overall mean and for each country. The tests show if there is a significant difference from 0 for each attribute. If there is, then the attribute is significantly above average importance and thus should be taken into consideration.

The results are based on the assumptions that each population is approximately normally distributed and there are equal population variances. Central Limit theorem can be used as the basis for normality due to the large sample sizes. The samples were independent and selected at random. A one tail t-test was used at a significance level of $5 \%$. Therefore, if the $\mathrm{p}$ value is less than 0.05 , the zero hypothesis is rejected, and the attribute is of significant importance.

\section{Significant attributes: for Africa}

For the overall mean of each service attribute, the findings in Table 8 show that only seven (out of fifteen) service attributes proved to be of significant importance $(\mathrm{p}<0.05)$.

These were: efficient staff; shorter queues; fast response times; service reliability; convenient locations; friendly staff; and understanding personal banking needs. Conversely, insignificant attributes with a negative overall mean or a $p$ value greater than 0.05 included: Appearance of facilities; Welcoming environment; After sales service; Good advice; Good product knowledge; Feedback on processes; Feedback provided timeously; and Building long term relationships

\section{Significant attributes: by country}

When delineating what the similarities in significant attributes are across the ten countries, only efficient staff and shorter queues were significant for each and every country, based on the low p values for these two attributes in Table 7. Appearance of facilities, providing a welcoming environment and good product knowledge proved to be insignificant attributes for all ten countries. On average, the countries tended to only have 6 significant attributes, out of the 15 total attributes. The results highlight some of the key determinants of service quality in Africa, and provide managers of multinational companies with a framework of similarities that exist across countries when assessing service quality.

\section{Significant dimensions: by country}

Analysis of significant dimensions by country demonstrates the following similarities and differences. The most critical dimension "responsiveness" is consistently the same for all countries, and supports the proposition which proposes that "responsiveness" is the most important dimension. Thereafter, the dimensional rankings vary by country, showing minor similarities. Kenya and Zambia followed the same service dimensional ranking as the overall ranking for Africa i.e. (1) responsiveness, (2) reliability, (3) tangibles, (4) assurance, and (5) empathy. Ghana and Tanzania were the only other two countries displaying an identical dimensional ranking, i.e.: (1) responsiveness, (2) assurance, (3) tangibles, (4) reliability. None of the African countries followed the full ranking proposed in the second proposition: (1) responsiveness, (2) assurance, (3) empathy, (4) tangibles, (5) reliability. While partial similarities are 
evident, it is clear that cross-national differences across most countries are prevalent. Furthermore, "responsiveness" being the most important dimension is the only similarity between African countries and the UK.

\section{Conclusions and recommendations}

\section{Conclusions}

The objective of this study was to analyse customer service expectations in retail banking in Africa. The following conclusions were derived from this research for the respective propositions:

Research Proposition 1:

\section{Customer service expectations in retail banking differ significantly between countries in Africa}

The research clearly shows that customer service expectations in retail banking do differ significantly between countries in Africa: Proposition one is therefore supported. ANOVA testing presents sufficient evidence to indicate that for every service attribute, one or more of the population (country) means are not equal to the others. Every attribute had some significant difference between countries. This implies that different cultural groups give different importance to service quality dimensions. It is therefore critical to take cross-national differences into consideration when designing and implementing a marketing strategy for multinational banks and financial institutions. In order to achieve this, country-specific customer expectations must be determined and prioritised as a first step towards improving service quality.

Research Proposition 2:

The importance ranking of the service dimensions in African retail banking are: 1. Responsiveness; 2. Assurance; 3. Empathy; 4". Tangibles and Reliability

The relative importance of the underlying SERVQUAL dimensions in this survey show partial variance to those identified by past research: Proposition two is partially supported.

\section{Ranking: Service dimensions}

This study has determined that in an African context, responsiveness, reliability, tangibles, assurance and empathy are the most important dimensions relating to retail banking services.

This assessment is based on the ranking of individual attributes collapsed into the underlying dimensions. The data from the survey is derived from a partial rank ordering technique. Customers overwhelmingly perceive responsiveness (the time dimension of service quality) to be of vital importance, ranked first out of the five service dimensions. This supports previous research by Avkiran (1994), Blanchard and Galloway (1994), and Johnston (1997) which indicates that responsiveness would attract the highest rating in the retail banking sector, and is consistent with Karatepe et al.'s (2005) findings that, in a developing country, interaction quality (i.e. responsiveness and assurance) is the most important dimension. Of interest though is that the relative importance ranking of subsequent service dimensions was not consistent with previous research. The results suggest that relational issues surrounding assurance and empathy are of less importance in an African context, while core dimensions such as responsiveness (driven by staff efficiency and shorter queues), and reliability (performing dependably and accurately) are more important. Consequently, cultural values are very important in guiding consumers in their evaluation of service quality: Imrie et al. (2002) found that for Taiwanese consumers, interpersonal relations, underlined by three major themes, sincerity, generosity, and courtesy/politeness, were critical determinants of service quality.

Both dimensions (responsiveness and reliability) tend to be more outcome based and can be classified as objective hard issues since they can be much more readily identified and specified than that of soft and subjective "relational" issues. This is also consistent with the findings of Greenland et al. (2006) in East Africa and Sureshchandar et al. (2003) in India, where issues regarding banking technology such as ATMs are important to bank customers. This implies that addressing the hard objective issues could more readily provide, and monitor, a high quality service in a fairly prescriptive and reproducible manner (Blanchard \& Galloway, 1994).

\section{Ranking: Service attributes}

This study also identifies the individual attributes that collectively drive the underlying dimensions. Staff efficiency is not only the most important attribute (on average) for retail banking customers in Africa, but it is perceived to be twice as important as having "shorter queues", ranked second. Service reliability and convenient locations are rated as the third and fourth most important attributes respectively (out of 15 attributes in total). Of least importance is having a welcoming environment and good product knowledge.

\section{Ranking: By country}

Cross-country analysis shows partial indifferences in the relative importance regarding dimensions and attributes. Staff efficiency (responsiveness) is the most important attribute (dimension) for each and every country, indicating that partial similarities of relative importance do exist across countries. This would suggest that efforts to increase speed of processing information and customers are likely to have an important and positive effect on customer satisfaction.

Furthermore, only one attribute (staff efficiency) appears to be stable cross-culturally. This demonstrates that clear differences are evident for each country, which calls for an understanding of cultural differences when designing country-specific marketing strategies. This is consistent with the conclusions of Malhotra et al. (2005), that culture is a key variable influencing the perceptions of service quality. 
Table 7: Importance ranking of standardised means, by country

\begin{tabular}{|c|c|c|c|c|c|c|c|c|c|c|c|c|}
\hline & Service Attributes & Bots & Egypt & Ghana & Kenya & Maur & Seych & Tanz & Ugan & Zam & Zim & $\begin{array}{c}\text { Overall } \\
\text { Mean }\end{array}$ \\
\hline \multirow{5}{*}{ 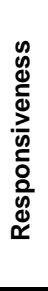 } & Efficient staff & 1.101 & 0.988 & 0.800 & 0.779 & 0.518 & 0.882 & 0.864 & 0.836 & 0.905 & 0.769 & 0.844 \\
\hline & Shorter queues & 0.416 & 0.925 & 0.403 & 0.249 & 0.409 & 0.259 & 0.544 & 0.278 & 0.245 & 0.399 & 0.413 \\
\hline & Provides feedback on processes & -0.178 & -0.204 & -0.241 & -0.190 & -0.169 & -0.044 & -0.004 & -0.334 & -0.585 & 0.089 & -0.186 \\
\hline & Feedback is provided timeously & -0.181 & -0.716 & -0.167 & -1.023 & -0.534 & -0.838 & 0.059 & 0.109 & -0.446 & -0.269 & -0.401 \\
\hline & Response time to info requests & -0.066 & 0.428 & 0.165 & 0.322 & 0.303 & 0.510 & -0.119 & 0.094 & 0.037 & 0.167 & 0.184 \\
\hline 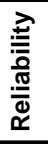 & Reliability & 0.419 & 0.066 & 0.234 & 0.761 & 0.114 & -0.022 & 0.097 & 0.342 & 0.422 & 0.610 & 0.304 \\
\hline \multirow{3}{*}{ 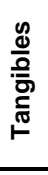 } & Appearance of facilities & -0.357 & -0.477 & -0.303 & -0.250 & -0.173 & -0.370 & -0.168 & -0.375 & -0.326 & -0.571 & -0.337 \\
\hline & Convenient locations & 0.015 & 0.161 & 0.354 & 0.481 & -0.065 & -0.068 & 0.285 & 0.475 & 0.419 & 0.318 & 0.237 \\
\hline & Provides a welcoming environment & -0.487 & -0.810 & -0.447 & -0.542 & -0.177 & -0.266 & -0.299 & -0.672 & -0.288 & -0.799 & -0.479 \\
\hline \multirow{4}{*}{ 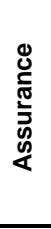 } & Friendly staff & 0.022 & 0.117 & 0.586 & 0.069 & 0.299 & 0.019 & 0.480 & 0.203 & 0.191 & -0.141 & 0.184 \\
\hline & After sales service & -0.313 & 0.048 & -0.360 & -0.282 & 0.043 & 0.513 & -0.453 & -0.343 & -0.201 & -0.165 & -0.151 \\
\hline & Provides good advice & -0.232 & -0.348 & -0.255 & -0.166 & 0.063 & 0.269 & -0.399 & -0.324 & -0.172 & -0.318 & -0.188 \\
\hline & Good product knowledge & -0.040 & -0.309 & -0.440 & -0.677 & -0.547 & -0.766 & -0.364 & -0.404 & -0.359 & -0.546 & -0.445 \\
\hline \multirow{2}{*}{ 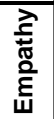 } & Building long term relationships & -0.356 & -0.222 & -0.249 & 0.088 & -0.257 & -0.254 & -0.224 & -0.190 & 0.030 & 0.018 & -0.161 \\
\hline & Understands personal banking needs & 0.236 & 0.352 & -0.080 & 0.383 & 0.173 & 0.176 & -0.299 & 0.304 & 0.127 & 0.438 & 0.181 \\
\hline
\end{tabular}

Note:

- The higher the mean, the more important that aspect of service delivery is to the respondents

- Negative means are inconsequential since they represent a less than average importance

- Positive means are represented in black. Negative means are represented in grey.

- The data has been standardised, therefore the overall mean $=0$, and the overall standard deviation $=1$

- The overall mean was derived from the individual country means

- No weighting was applied to the overall mean in order to give each country equal importance

Table 8: Significance of attribute means by country

\begin{tabular}{|c|c|c|c|c|c|c|c|c|c|c|c|}
\hline & \multirow[t]{2}{*}{ Service Attributes $\quad$ (Q4 2006) } & \multicolumn{2}{|l|}{ Bots } & \multicolumn{2}{|l|}{ Egypt } & \multicolumn{2}{|l|}{ Ghana } & \multicolumn{2}{|l|}{ Kenya } & \multirow{2}{*}{$\begin{array}{c}\text { Maur } \\
\bar{X} \\
\end{array}$} & \multirow[b]{2}{*}{ P Value } \\
\hline & & $\overline{\bar{X}}$ & P Value & $\bar{x}$ & P Value & \begin{tabular}{l|l}
$\bar{X}$ & \\
\end{tabular} & P Value & $\overline{\bar{X}^{\prime}}$ & P Value & & \\
\hline \multirow{5}{*}{ 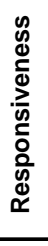 } & Efficient staff & 1.101 & 0.000 & 0.988 & 0.000 & 0.800 & 0.000 & 0.779 & 0.000 & 0.518 & 0.000 \\
\hline & Shorter queues & 0.416 & 0.000 & 0.925 & 0.000 & 0.403 & 0.000 & 0.249 & 0.000 & 0.409 & 0.000 \\
\hline & Provides feedback on processes & -0.178 & NA & -0.204 & NA & -0.241 & NA & -0.190 & NA & -0.169 & NA \\
\hline & Feedback is provided timeously & -0.181 & NA & -0.716 & NA & -0.167 & NA & -1.023 & NA & -0.534 & NA \\
\hline & Response time to info requests & -0.066 & NA & 0.428 & 0.000 & 0.165 & 0.000 & 0.322 & 0.000 & 0.303 & 0.000 \\
\hline 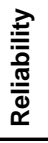 & Reliability & 0.419 & 0.000 & 0.066 & 0.092 & 0.234 & 0.000 & 0.761 & 0.000 & 0.114 & 0.010 \\
\hline \multirow{3}{*}{ 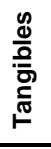 } & Appearance of facilities & -0.357 & NA & -0.477 & NA & -0.303 & NA & -0.250 & NA & -0.173 & NA \\
\hline & Convenient locations & 0.015 & 0.344 & 0.161 & 0.001 & 0.354 & 0.000 & 0.481 & 0.000 & -0.065 & NA \\
\hline & Provides a welcoming environment & -0.487 & NA & -0.810 & NA & -0.447 & $\mathrm{NA}$ & -0.542 & $\mathrm{NA}$ & -0.177 & NA \\
\hline \multirow{4}{*}{ 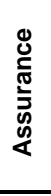 } & Friendly staff & 0.022 & 0.279 & 0.117 & 0.009 & 0.586 & 0.000 & 0.069 & 0.032 & 0.299 & 0.000 \\
\hline & After sales service & -0.313 & NA & 0.048 & 0.164 & -0.360 & NA & -0.282 & NA & 0.043 & 0.191 \\
\hline & Provides good advice & -0.232 & NA & -0.348 & NA & -0.255 & NA & -0.166 & NA & 0.063 & 0.101 \\
\hline & Good product knowledge & -0.040 & NA & -0.309 & NA & -0.440 & NA & -0.677 & NA & -0.547 & NA \\
\hline \multirow{2}{*}{ 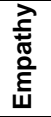 } & Building long term relationships & -0.356 & NA & -0.222 & NA & -0.249 & NA & 0.088 & 0.009 & -0.257 & NA \\
\hline & Understands personal banking needs & 0.236 & 0.000 & 0.352 & 0.000 & -0.080 & NA & 0.383 & 0.000 & 0.173 & 0.000 \\
\hline
\end{tabular}




\begin{tabular}{|c|c|c|c|c|c|c|c|c|c|c|c|}
\hline & \multirow[t]{2}{*}{ Service Attributes (Q4 2006) } & \multicolumn{2}{|l|}{ Seych } & \multicolumn{2}{|l|}{ Tanz } & \multicolumn{2}{|l|}{ Ugan } & \multicolumn{2}{|l|}{ Zam } & \multicolumn{2}{|l|}{ Zim } \\
\hline & & \begin{tabular}{|l|l|l|}
$\bar{x}$ & $\bar{X}$ \\
\end{tabular} & P Value & $\bar{x}$ & P Value & $\bar{x}$ & P Value & \begin{tabular}{l|l}
$\bar{x}$ & 1 \\
\end{tabular} & P Value & $\overline{\bar{X}}$ & P Value \\
\hline \multirow{5}{*}{ 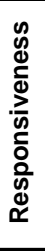 } & Efficient staff & 0.882 & 0.000 & 0.864 & 0.000 & 0.836 & 0.000 & 0.905 & 0.000 & 0.769 & 0.000 \\
\hline & Shorter queues & 0.259 & 0.000 & 0.544 & 0.000 & 0.278 & 0.000 & 0.245 & 0.000 & 0.399 & 0.000 \\
\hline & Provides feedback on processes & -0.044 & NA & -0.004 & $\mathrm{NA}$ & -0.334 & NA & -0.585 & NA & 0.089 & 0.014 \\
\hline & Feedback is provided timeously & -0.838 & $\mathrm{NA}$ & 0.059 & 0.149 & 0.109 & 0.016 & -0.446 & NA & -0.269 & NA \\
\hline & Response time to info requests & 0.510 & 0.000 & -0.119 & $\mathrm{NA}$ & 0.094 & 0.031 & 0.037 & 0.191 & 0.167 & 0.000 \\
\hline 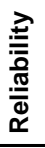 & Reliability & -0.022 & NA & 0.097 & 0.045 & 0.342 & 0.000 & 0.422 & 0.000 & 0.610 & 0.000 \\
\hline \multirow{3}{*}{ 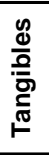 } & Appearance of facilities & -0.370 & NA & -0.168 & $\mathrm{NA}$ & -0.375 & $\mathrm{NA}$ & -0.326 & NA & -0.571 & NA \\
\hline & Convenient locations & -0.068 & NA & 0.285 & 0.000 & 0.475 & 0.000 & 0.419 & 0.000 & 0.318 & 0.000 \\
\hline & Provides a welcoming environment & -0.266 & NA & -0.299 & $\mathrm{NA}$ & -0.672 & NA & -0.288 & NA & -0.799 & NA \\
\hline \multirow{4}{*}{ 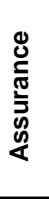 } & Friendly staff & 0.019 & 0.383 & 0.480 & 0.000 & 0.203 & 0.000 & 0.191 & 0.000 & -0.141 & NA \\
\hline & After sales service & 0.513 & 0.000 & -0.453 & $\mathrm{NA}$ & -0.343 & $\mathrm{NA}$ & -0.201 & NA & -0.165 & NA \\
\hline & Provides good advice & 0.269 & 0.000 & -0.399 & $\mathrm{NA}$ & -0.324 & $\mathrm{NA}$ & -0.172 & NA & -0.318 & NA \\
\hline & Good product knowledge & -0.766 & $\mathrm{NA}$ & -0.364 & $\mathrm{NA}$ & -0.404 & $\mathrm{NA}$ & -0.359 & $\mathrm{NA}$ & -0.546 & NA \\
\hline \multirow{2}{*}{ 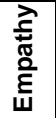 } & Building long term relationships & -0.254 & $\mathrm{NA}$ & -0.224 & $\mathrm{NA}$ & -0.190 & $\mathrm{NA}$ & 0.030 & 0.237 & 0.018 & 0.327 \\
\hline & Understands personal banking needs & 0.176 & 0.003 & -0.299 & $\mathrm{NAl}$ & 0.304 & 0.000 & 0.127 & 0.001 & 0.438 & 0.000 \\
\hline
\end{tabular}

Note assumptions:

- One tail t-test, Significance level: $5 \%(\alpha=0.05)$. X bar $=$ mean

- Significant attributes are represented in black. Insignificant attributes are represented in grey

- NA (Not Applicable): The P value results relating to negative means would imply the attribute is insignificant and therefore not applicable, since we are testing for above average ( 0$)$ importance using a one tail t-test.

- The data has been standardised, therefore the overall mean $=0$, and the overall standard deviation $=1$

\section{Significant attributes: For Africa}

Results from the t-tests used to determine the significance of attributes indicate that only seven (out of fifteen) service attributes proved to be of significant importance (i.e. significantly above average importance). These were efficient staff, shorter queues, fast response times, service reliability, convenient locations, friendly staff, and understanding personal banking needs.

Conversely, insignificant attributes with a below average importance included appearance of facilities, providing a welcoming environment, after sales service, good advice, good product knowledge, feedback on processes, feedback provided timeously, and building long term relationships.

\section{Significant attributes: By country}

When delineating what the similarities in significant attributes are across the ten countries, only efficient staff and shorter queues were significant for each and every country. Appearance of facilities, providing a welcoming environment and good product knowledge proved to be insignificant attributes for all ten countries. Any time and money put into these areas (over and above the standard offering) might be better redirected elsewhere.

The above results highlight some of the key determinants of service quality in Africa, and provide managers of multinational companies with a framework of similarities that exist across countries. If detailed branch analysis is not available, this research highlights two general areas that banks need to focus their attention on in order to achieve an advantage.

\section{Significant dimensions: by country}

Analysis of significant dimensions by country reiterates that "responsiveness" is consistently the most important for all countries. Thereafter, the dimensional rankings vary by country, showing minor similarities.

Kenya and Zambia followed the same dimensional ranking as the overall ranking for Africa: (1) responsiveness, (2) reliability, (3) tangibles, (4) assurance, (5) empathy. Ghana and Tanzania were the only other two countries displaying an identical dimensional ranking i.e.: (1) responsiveness, (2) assurance, (3) tangibles, and (4) reliability. None of the African countries followed the full ranking proposed in the second proposition, i.e. (1) responsiveness, (2) assurance, (3) empathy, (4) tangibles, and (5) reliability.

While partial similarities are evident, it is clear that crossnational differences across most countries are prevalent. Furthermore, responsiveness being the most important dimension is the only similarity between African countries and the UK.

\section{Recommendations to management}

The results of this research provide a number of clear implications for the management of customer service expectations. Cross-national differences are clearly evident across countries in Africa, which calls for customised 
marketing strategies based on the unique customer service expectations that exist for each country. However some similarities are evident for certain dimensions and attributes, which can be leveraged off for a pan-African strategy. Customers of retail banks in Africa are clearly seeking a responsive service, with a high level of staff efficiency. This would suggest that efforts to increase speed of processing information and customers are likely to have an important and positive effect on customer satisfaction. Addressing this issue through regular staff training should improve service quality. Shorter queues, service reliability and convenient locations are also considered to be very important by customers. Furthermore, these attributes (including staff efficiency) are becoming increasingly important over time. For retail banks in Africa wanting to enhance customer satisfaction, these would be key areas for improvement. These are areas where well-designed routines and responses could be used to gain maximum impact. Time and money, beyond a basic provision, invested in providing a welcoming environment, appearance of facilities and good product knowledge can be better redirected elsewhere.

\section{Limitations of the research}

While this study was an extensive research of ten African countries with a large sample size, it is limited by the instrument used, i.e. a questionnaire based on the 5 SERVQUAL dimensions, with the associated limitations identified in the literature. It consequently did not capture other dimensions that could be important to consumers of banking services in these countries, such as banking technology (Greenland et al., 2006; Sureshchandar et al., 2003) or machine service quality (Aldlaigan \& Buttle, 2005), or image and values (the extent to which the services of an organisation fit the values of customers) (Jabnoun \& Khalifa, 2005). It also did not test the two additional dimensions recommended by the BSQ model of Bahia and Nantel (2000), i.e. price and services portfolio, which could have been important to consumers in Africa.

The quantitative analysis was done using a comparative scaling technique applying a partial rank order scale, as an alternative to other methods such as factor analysis and multiple regression: a comparison between the methods could reveal further insights.

\section{Recommendations for future research}

Concerning future investigations, further research must be conducted in order to explore how cultural differences shape perceptions and expectations of service quality, by way of exploring psychometric properties and culture value orientations.

Researchers should also consider taking a broader view towards identifying the components of service quality and the overall service offering. The components should encompass not only the recently identified external constructs relating to customer expectations, but also the internal issues relating to employee satisfaction that drive service quality.
New frameworks and techniques should also be applied to compare traditional SERVQUAL study results with other methods. Research in banking service quality could be conducted using BSQ, SYSTRA-SQ, or a customised model reflecting cultural and industry-specific dimensions. In addition, other data collection and analytical techniques could also be utilised, such as factor analysis of service quality statements, the Critical Incident Method or observation (Smith \& Reynolds, 2002), or structural equation modelling (Imrie et al., 2002), to provide further insights into the dimensions of service quality, and hence the marketing programmes necessary to address the consumer expectations.

\section{References}

Aldlaigan, A. \& Buttle, F. 2005. 'Beyond satisfaction: Customer attachment to retail banks,' International Journal of Bank Marketing, 23(4): 349-59.

Arasli, H., Katircioglu, S.T. \& Mehtap-Smadi, S. 2005. 'A comparison of service quality in the banking industry', International Journal of Bank Marketing, 23(6/7):508-526.

Avkiran, N.K. 1994. 'Developing an instrument to measure customer service in branch banking', International Journal of Bank Marketing, 12(6):10-18.

Bahia, K. \& Nantel, J. 2000. 'A reliable and valid measurement scale for the perceived service quality of banks', International Journal of Bank Marketing, 18(2):8491.

Baumann, C., Burton, S., Elliott, G. \& Kehr, H.M. 2007. 'Prediction of attitude and behavioural intentions in retail banking', International Journal of Bank Marketing, 25(2):102-116.

Bhat, M.A. 2005. 'Correlates of service quality in banks: An empirical investigation', Journal of Services Research, 5(1):77-99.

Bitner, M.J., Booms, B.H. \& Tetreault, M.S. 1990. 'The service encounter: Diagnosing favorable and unfavorable incidents', Journal of Marketing, 54(1):71-84.

Blanchard, R.F. \& Galloway, R.L. 1994. 'Quality in retail banking', International Journal of Service Industry Management, 5(4):5-23.

Boshoff, C. \& Nel, D. 1992. 'Influence of demographic variables on service quality perceptions in three industries', South African Journal of Business Management, 23(3/4): 69-74.

Boulding, W., Kalra, A., Staelin, R. \& Zeithaml, V.A. 1993. 'A dynamic process model of service quality: From expectations to behavioural intentions', Journal of Marketing Research, 30(1):7-27.

Carman, J.M. 1990. 'Consumer perceptions of service quality: An assessment of the SERVQUAL dimensions', Journal of Retailing, 66(1):33-55. 
Davidow, W. H. \& Uttal, B. 1989. 'Service companies:focus or falter', Harvard Business Review, 67 (4): 17-34.

Espinoza, M.M. 1999. 'Assessing the cross-cultural applicability of a service quality measure - A comparative study between Quebec and Peru', International Journal of Service Industry Management, 10(5): 449-468.

Gilbert, G.R. \& Veloutsou, C. 2006. 'A cross-industry comparison of customer satisfaction', Journal of Services Marketing, 20(5):298-308.

Greenland, S., Coshall, J. \& Combe, I. 2006. 'Evaluating service quality and consumer satisfaction in emerging markets', International Journal of Consumer Studies, 30(6):582-590.

Grönroos, C. 1988. 'Service quality: The six criteria of good perceived service', Review of Business, 9(3):10-14.

Imrie, B.C., Cadogan, J.W. \& McNaughton, R. 2002. 'The service quality construct on a global stage', Managing Service Quality, 12(1):10-18.

Islam, N. \& Ahmed, E. 2005. 'A measurement of customer service quality of banks in Dhaka City of Bangladesh', South Asian Journal of Management, 12(1):37-57.

Jabnoun, N. \& Al-Tamimi, A.H. 2003. 'Measuring perceived service quality at UAE commercial banks', International Journal of Quality \& Reliability Management, 20(4):458-472.

Jabnoun, N. \& Khalifa, A. 2005. 'A customized measure of service quality in the UAE', Managing Service Quality, 15(4):374-388.

Johnson, C. \& Mathews, B.P. 1997. 'The influence of experience on service expectations', International Journal of Service Industry Management, 8(4):290-305.

Johnston, R. 1997. 'Identifying the critical determinants of service quality in retail banking: Importance and effect', International Journal of Bank Marketing, 15(4):111-116.

Karatepe, O.M., Yavas, U. \& Babakus, E. 2005. 'Measuring service quality of banks: Scale development and validation', Journal of Retailing and Consumer Services, 12(5): 373-383.

Knight, G. 1999. 'International services marketing: Review of research, 1980-1998' International Journal of Services Marketing, 13(4/5):347-360.

Ladhari, R. 2008. 'Alternative measures of service quality: A review', Managing Service Quality, 18(1):65-86.

Lassar, W. M., Manolis, C. \& Winsor, R. D. 2000. 'Service quality perspectives and satisfaction in private banking, Journal of Services Marketing,14 (3): 244-271
Leedy, P.D. \& Ormrod, J.E. 2001. Practical research: Planning and design. $7^{\text {th }}$ Edition. Upper Saddle River: Merrill Prentice Hall.

Lovelock, C.H. 1999. 'Developing marketing strategies for transnational service operations', Journal of Services Marketing: 13(4/5):278-289.

Malhotra, N.K., Ulgado, F.M., Agarwal, J., Shainesh, G. \& $\mathrm{Wu}, \mathrm{L}$. 2005. 'Dimensions of service quality in developed and developing economies: Multi-country cross-cultural comparisons', International Marketing Review, 22(3):256278.

Najjar, L. \& Bishu, R.R. 2006. Service quality: A case study of a bank', The Quality Management Journal, 13(3):35-44.

Nel, D., Pitt, L.F. \& Berthon, P.R. 1997. 'The SERVQUAL Instrument: Reliability and validity in South Africa', South African Journal of Business Management, 28(3):113-122.

Parasuraman, A., Zeithaml, V.A. \& Berry, L.L. 1985. 'A conceptual model of service quality and its implications for future study', Journal of Marketing, 49(4):41-50.

Parasuraman, A., Zeithaml, V.A. \& Berry, L.L. 1988. 'SERVQUAL: A multiple-item scale for measuring consumer perceptions of service quality', Journal of Retailing, 64(1):12-40

Parasuraman, A., Berry, L.L. \& Zeithaml, V.A. 1990. 'Guidelines for conducting service quality research', Marketing Research, 2(4):34-44.

Parasuraman, A., Berry, L.L. \& Zeithaml, V.A. 1991. 'Understanding customer expectations of service', Sloan Management Review; 39(3):39-48.

Parasuraman, A., Zeithaml, V.A. \& Berry, L.L. 1993. 'More on improving service quality measurement', Journal of Retailing, 69(1):140-147.

Parasuraman, A., Zeithaml, V.A. \& Berry, L.L. 1994. 'Reassessment of expectations as a comparison standard in measuring service quality: Implications for further research', Journal of Marketing, 58(1):111-125.

Petridou, E., Spathis, C., Glaveli, N. \& Liassides, C. 2007. 'Bank service quality: Empirical evidence from Greek and Bulgarian retail customers', International Journal of Quality \& Reliability Management, 24(6):568-585.

Pitt, L., Morris, M.H. \& Oosthuizen, P. 1996. 'Expectations of service quality as an industrial market segmentation variable', The Service Industries Journal, 16(1):1-9.

Reichheld, F. 2003. 'The one number you need to grow', Harvard Business Review, 81(12):46-55.

Robledo, M.A. 2001. 'Measuring and managing service quality: Integrating customer expectations', Managing Service Quality, 11(1):22-31. 
Smith, A.M. \& Reynolds, N.L. 2002. 'Measuring crossnational service quality - A framework for assessment', International Marketing Review, 19(5):450-481.

Speece, M. \& Pinkaeo K. 2002. 'Service expectations and consumer ethnocentrism', Australasian Marketing Journal, 10(3):59-75.

Stauss, B. \& Mang, P. 1999. " "Culture shocks" in intercultural service encounters?', Journal of Services Marketing, 13(4/5):329-346.

Sureshchandar, G.S., Rajendran, C. \& Anantharaman, R.N. 2003. 'Customer perceptions of service quality in the banking sector of a developing economy: A critical analysis', International Journal of Bank Marketing, 21(5):233-242.

Tersine, R. \& Harvey, M. 1998. 'Global customerization of markets has arrived!' European Management Journal, 16(1):45-57.

Webster, C. 1989. 'Can consumers be segmented on the basis of their service quality expectations?', Journal of Services Marketing, 2(3):35-53.

World Trade Organisation. 2005. 'International Trade Statistics 2005'. [online]

URL:http://www.wto.org/english/res_e/statis_e/its2005_e/it s05_bysector_e.pdf.

Yavas, U. \& Benkenstein, M. 2007. 'Service quality assessment: A comparison of Turkish and German bank customers', Cross-Cultural Management: An International Journal, 14(2):161-168.

Zeithaml, V.A., Parasuraman, A. \& Berry, L.L. 1990. Delivering quality service. New York: The Free Press. 
